\title{
Needs, Expectations, and Experiences of International Students in Pathway Program in the United States
}

\author{
Eman Elturki $^{\mathrm{a}}$, Yang Liu ${ }^{\mathrm{a}}$, Justyna Hjeltness ${ }^{\mathrm{a}}$ and Kate Hellmann $^{\mathrm{a}}$
}

\begin{abstract}
This research assesses the first cohort of pathway students' needs and their academic and sociocultural experiences at a US university. A needs analysis survey, individual student interviews, and a follow-up survey were used for data collection. Understanding lectures, completing assignments, and building social relationships with domestics were among the challenges faced by pathway students due to linguistic and cultural barriers. An additional unique challenge for this particular population of international students centered around the fact that they tackle disciplinerelated courses while still refining their English skills. Additional support services to help students in pathways academically and socioculturally are crucial.
\end{abstract}

Keywords: academic challenges, graduate pathways, sociocultural factors, undergraduate pathways

\section{Introduction}

The number of international students at U.S. universities has been steadily growing in recent years. During the 2016-2017 academic year, it was estimated that the total number of international students in the United States was 1,078,822 (Institute of International Education [IIE], 2017). The presence of international students has benefited the United States in various ways. International students have impacted universities and colleges positively by contributing to research efforts, bringing diverse perspectives to the classroom, and providing opportunities for domestic students to develop cross-cultural competence, especially for those who have not had the opportunity to study abroad (IIE, 2017; Urban \& Palmer, 2014). Beyond the academic impact, international students have also contributed to the U.S. economy. Based on data compiled by the U.S. Department of Commerce, the contribution of international students to the U.S. economy in 2016 was $\$ 39.4$ billion (IIE, 2017). They also provided over 450,000 jobs in the United States during 2017 (NAFSA: Association of International Educators [NAFSA], 2017).

\footnotetext{
a Washington State University.
} 
Although the United States has been an attractive destination for international students, there is concern regarding a decrease in international student numbers. In fact, many intensive English programs have experienced a considerable decline in enrollment in recent years. According to a 2017 Open Doors report on intensive English-language student data (IIE, 2017), a decline in enrollment from the following countries had been observed during 2017 as compared to 2015: Brazil -56.2\%, Saudi Arabia $-45.2 \%$, Vietnam $-35.6 \%$, Kuwait $-30 \%$, Oman $-30 \%$, India $-20.7 \%$, China $-16 \%$, and South Korea $-13.2 \%$. Some of the variables that have contributed to the drop in these numbers are cuts in scholarship programs in some countries such as Saudi Arabia and Brazil, difficulties in obtaining a U.S. visa, as well as the increase in language programs in students' home countries. Some observers predict that this decline may accelerate and result in significant shifts in international student numbers and demographics due to the current political climate and changes in policies after the 2016 U.S. presidential election (Altbach \& de Wit, 2017).

Despite these concerns, the majority of U.S. universities are committed to the mission of internationalization. In response to recent political events, some U.S. universities have taken actions to support international students. A 2017 survey by IIE showed that more than $50 \%$ of the surveyed universities indicated that they issued a statement supporting international students, provided opportunities for students to discuss U.S. social and political events, and/or offered counseling for students who were concerned about the U.S. social and political climate. Internationalizing higher education has been a continuing effort and a crucial element in the strategic planning of many universities. Many institutions have systematically and actively sought ways to internationalize their campuses. For instance, some institutions have taken concrete steps to realize their mission of internationalization by working in partnership with a third party to increase international student numbers. Washington State University (WSU), for example, partnered with INTO, a private sector company that serves as a "bridge between students seeking higher education opportunities and universities who seek to internationalize their teaching, research and engagement around the world" (INTO University Partnerships, 2018). This move was part of the internationalization effort included in WSU's "Drive to 25" initiative (Lawson, 2016). WSU's level of internationalization is currently at 7.1\%, which is low compared with other peer institutions standing at $18 \%-20 \%$ Washington State University's Office of International Programs \& Office of the Provost, 2016). INTO was launched in the United States in 2008 to provide a joint venture model to facilitate the recruitment of international students. According to INTO University Partnerships (2018), "In just eight years Oregon State University has grown international enrollments from 970 to 4,000 , six times the U.S. average, while improving its ranking." INTO WSU was fully launched in Fall 2017 with a total number of 157 new students. Academic English programs and pathway programs are offered. In the academic English program, students focus on English as a second language (ESL) only, whereas in the pathway programs, students refine their English language skills while taking academic courses in their majors concurrently before becoming degree-seeking students after exiting the pathway programs. Pathway programs are offered to both undergraduate and graduate students in different lengths depending on students' English language proficiency test scores at entry: comprehensive 
undergraduate pathway (UP), two-semester UP, two-semester graduate pathway (GP), and one-semester UP/GP. This paper reports on results from a longitudinal research project that was initiated to assess the first cohort of pathway students' needs and their academic and sociocultural experiences at INTO WSU, and, accordingly, identifies ways to enhance students' experiences.

\section{Literature Review}

The growing population of international students has received increased attention in recent years. Continuing efforts have been made to understand the challenges that international students go through during their pursuits of academic degrees in Englishspeaking countries. Researchers have reported that international students face both academic and cultural obstacles (e.g., Caplan \& Stevens, 2017; Gebhard, 2012; Lin \& Scherz, 2014; Perry, 2016). Academic challenges are related to the inability to function effectively in classroom settings. Recurrent academic issues reported in the literature were related to participation in classroom discussions, limited collaboration opportunities with domestic peers, and lack of clarity in international students' understanding of degree requirements (Caplan \& Stevens, 2017; Lin \& Scherz, 2014; Perry, Weatherford, \& Lausch, 2016). International students also struggle with understanding lectures, and they spend a substantial time and effort when reading academic texts and completing writing assignments (Kuo, 2011; Lin \& Scherz, 2014). Effective communication with professors and domestic peers has also been reported as another challenge for international students. $\mathrm{Wu}$, Garza, and Guzman (2015) stated that international students struggle to communicate effectively with faculty and classmates due to language barriers and a lack of proper understanding of effective interactions in the foreign culture. Although most of the new generations are tech-savvy, technology was described as another hurdle for international students. Some of these technological issues were related to the navigation of student online portals such as Blackboard, participating in virtual courses, completing online assignments, and typing effectively and efficiently in English (Banjong, 2015; Perry, 2016).

Other studies have looked at international students' adaption and adjustment to their new environments. Studies show that international students experience cultural shock owing to different cultural values and beliefs. As a result, they struggle with blending in their new homes and in developing friendships with locals. Hommadova (2017) studied the phases of adjustment of East Asian students in the United States and described that the participants may have adapted to the new environment but still "failed to integrate into the local culture, and chose to interact with co-ethnic or other international students" (p. 189). Wu and colleagues (2015) explained that cultural challenges include adjusting to "the different ways of thinking and doing in the US" (p. 1). In Wu et al.'s (2015) study, the participants expressed that they felt discriminated against both in academic and social settings and that their "American peers might not understand their backgrounds, and they made conclusions for them" (p. 6). Interestingly, the participants in the same study demonstrated willingness to disseminate their cultures and help their American classmates learn about their backgrounds. Kusek (2015) also found that international students have a strong connection with their host campus but a low degree of involvement 
with the local community. Chen (2018) explained that the limited sense of belonging that international students experience is a result of linguistic and cultural barriers.

Some studies have examined the strategies or coping mechanisms that international students utilize to overcome some of the aforementioned academic and cultural obstacles. For instance, some studies reported that recording lectures helped students review and retain the information and that visiting places in the community, such as churches, helped them enhance their speaking and socializing with native English speakers (Wu et al., 2015). Learning about American sports, utilizing the campus gym, and exchanging food with neighbors were other cultural strategies that international students sought to develop a higher degree of integration into the new culture (Wu et al., 2015). Research also shows that international students make use of campus resources, such as the writing center, participate in school activities, seek language support, and join student organizations as additional strategies (Wu et al., 2015; Zhou, Frey, \& Bang, 2011).

It can be understood from the snapshot of the literature that international students face numerous issues when studying in the United States. Language proficiency is the main barrier at both the academic and social levels (Perry et al., 2016). Although international students are able to obtain the required standardized test scores set by a given institution, this does not necessarily mean that they will not encounter linguistic and cultural issues when they join American universities. "Students are required to understand classroom interaction and other communications no matter how good they were on the [TOEFL/IELTS/GRE] tests" (Kuo, 2011, p. 41). The majority of the reviewed research looked at the experiences of international students who were fully matriculated as undergraduate and/or graduate students in institutions of higher education in the United States; however, there is still a need for research on international students in pathway programs. This research intends to add to this body of literature by shedding light on pathway systems in which international students study both English language classes and discipline-related courses. More specifically, this study reports on a longitudinal research project that was initiated in Fall 2017 after the full launch of INTO WSU to (a) assess the first cohort of undergraduate and graduate pathway students' needs, academic and sociocultural expectations, and perceptions of academic success, (b) monitor their academic and sociocultural experiences in pathway programs, and (c) plan ways to enhance students' experience based on the findings from this study. Specific research questions are:

What are the needs, academic and sociocultural expectations, and perceptions of academic success of pathway students at entry? What are the sociocultural and learning experiences of international undergraduate and graduate pathway students in U.S. higher education?

\section{Research Methods}

\section{Settings and Participants}

WSU is a public research university in the United States. This study took place in pathway programs at INTO WSU facilitated by the Intensive American Language Center (IALC). The IALC, an accredited English language program founded in 1984, services the INTO WSU partnership by providing academic English courses and pathways. This study focuses 
on the first cohort of students who were admitted into the two-semester undergraduate and graduate pathways and one-semester graduate pathways. The participants were predominately from China and India. The majority of the UP students were business and humanities majors while the GP students were largely from engineering and computer science. Informed consent protocols were followed for the data collection process.

\section{Data Collection and Analysis}

A descriptive research design was adopted to study "what" the academic and sociocultural experiences of international students in pathway programs in an American institution of higher education looked like. This research was also longitudinal in nature as data was collected from a cohort of participants at different times over two academic semesters using multiple instruments: a needs analysis survey at entry, individual student interviews at the end of the first semester, and a follow-up survey after midterms week during the second semester (Table 1). Survey completion and interview participation were voluntary. Descriptive statistical and thematic analyses were used to analyze the data. The following subsections describe the research instruments and procedures.

Table 1. Data collection instruments and timeline.

\begin{tabular}{lll}
\hline Data collection instrument & \multicolumn{1}{c}{ Timeline } & \multicolumn{1}{c}{ Date } \\
\hline Needs analysis survey & Early Semester 1 & Fall 2017 \\
Interviews & Late Semester 1 & Fall 2017 \\
Follow-up survey & Mid Semester 2 & Spring 2018 \\
\hline
\end{tabular}

\section{Needs Analysis Survey}

A needs analysis survey was administered upon entry into the program. Input from needs analysis is valuable to inform the planning, implementation, evaluation, and modification of a program (Richards, 2017). The survey elicited information on the participants' demographics including gender, age, nationality, program, and pathway type and track. A second component of the survey used Likert scales to gather responses pertaining to pathway students' self-reported knowledge about their own second language (L2) and academic competencies as well as their perceptions toward personal and sociocultural aspects that could affect their learning experience. This survey used a 4-point Likert scale (agree, somewhat agree, disagree, and somewhat disagree) without the inclusion of a neutral option to avoid midpoints and get solid responses about the participants' needs and perceptions (Bertram, 2012). A final section in the survey included open-ended questions to elicit more in-depth responses on the areas of English students would like to improve at INTO WSU, concerns regarding studying academic courses, as well as out-ofclass self-reported ways to improve their English and academic performance. The survey was developed using Qualtrics and sent via email to 75 students. Fifty-six students fully completed the survey (undergraduate $n=18$ and graduate $n=38$ ) yielding a $75 \%$ response rate. Frequency and percentage statistics, as well as thematic analyses, were used to 
analyze the data. To differentiate between the undergraduate and graduate experiences, a cross-tabulation of data was performed to treat the UP and GP participants as two groups even though they were part of the same survey.

\section{Student Interviews}

Semi-structured interviews were carried out through the end of the participants' first semester between November and December 2017 with a total number of 40 students (undergraduate $n=14$ and graduate $n=26$ ). Interviews consisted of two sets of questions; one set included 10 questions related to academic aspects of students' experiences during their first semester in the pathway programs, and the other set covered 10 questions concerning sociocultural aspects. The one-on-one interviews were recorded, transcribed, and coded. The data was analyzed thematically following the steps proposed by Braun and Clarke (2006). Emergent themes were grouped under broad a priori codes (e.g., academic challenges, cultural challenges, etc.) and supported with verbatim quotations from the participants to capture a clear picture of students' experiences. The analysis also included distinguishing between emergent themes pertaining to UP versus GP students.

\section{Follow-Up Survey}

Since this research is longitudinal in nature, a follow-up survey was designed using Qualtrics and sent to the same cohort of undergraduate and graduate students in March 2018 after midterms week during their second semester. Fifty-one of the participants (undergraduate $n=15$ and graduate $n=38$ ) responded to the follow-up survey yielding a $64 \%$ response rate. The survey consisted of three sets of Likert scale questions and two open-ended questions. The first set included questions regarding academic challenges, whereas the second set covered questions related to sociocultural challenges using a strongly agree-strongly disagree range. The third set asked students to indicate how often (using very frequently, frequently, occasionally, rarely, never, or NA) they had, for example, sought help from course instructors and advisors and utilized on-campus resources. The open-ended questions gave a chance for participants to describe their classroom experience at INTO WSU and share any specific challenges. The same procedures and analyses conducted to analyze the needs analysis survey data were used for this survey.

\section{Results}

\section{Findings from the Need Analysis Survey: Perceptions of Academic and Sociocultural Competencies and Needs at Entry}

This section reports on results from the needs analysis survey administered at entry. Demographic data is provided in Table 2. Data was converted to percentages to draw comparisons and contrasts between the UP and GP participants.

Overall, the 18 UP and 38 GP survey respondents seemed to feel positively about their academic abilities and the sociocultural aspects of studying in a foreign country as demonstrated by Figures 1 and 2 . However, by glancing at the same figures, it can be clearly seen that the GP respondents were more confident in their ratings than the UP students. 
Table 2. Demographics of undergraduate pathway (UP) and graduate pathway (GP) student survey respondents.

\begin{tabular}{|c|c|c|}
\hline & $\mathrm{UP}(\mathrm{n}=18)$ & $\mathrm{GP}(\mathrm{n}=38)$ \\
\hline Gender & $\begin{array}{l}\text { Male }=61 \%(n=11) \\
\text { Female }=39 \%(n=7)\end{array}$ & $\begin{array}{l}\text { Male }=74 \%(n=28) \\
\text { Female }=26 \%(n=10)\end{array}$ \\
\hline Age & $\begin{array}{l}18-19=61 \%(\mathrm{n}=11) \\
20 \mathrm{~s}=4 \%(\mathrm{n}=7)\end{array}$ & $\begin{array}{l}20 \mathrm{~s}=97 \%(\mathrm{n}=3) \\
30 \mathrm{~s}=3 \%(\mathrm{n}=1)\end{array}$ \\
\hline Nationality & $\begin{array}{l}\text { China }=61 \% \\
\text { South Korea }=11 \% \\
\text { Taiwan }=11 \% \\
\text { Indonesia }=6 \% \\
\text { Malaysia }=6 \% \\
\text { Thailand }=6 \%\end{array}$ & $\begin{array}{l}\text { India }=50 \% \\
\text { China }=29 \% \\
\text { Turkey }=11 \% \\
\text { Taiwan }=7 \% \\
\text { Armenia }=3 \%\end{array}$ \\
\hline Pathway track & $\begin{array}{l}\text { Business }=50 \% \\
\text { Humanities and social sci- } \\
\text { ences }=17 \% \\
\text { Computer science }=6 \% \\
\text { Fine arts }=6 \% \\
\text { Journalism } / \text { communication } \\
=5.56 \% \\
\text { Math }=6 \% \\
\text { Other }=11 \%\end{array}$ & $\begin{array}{l}\text { Computer science }=42 \% \\
\text { Mechanical engineering }=16 \% \\
\text { Architecture }=11 \% \\
\text { Electrical engineering }=8 \% \\
\text { Educational psychology = } 8 \% \\
\text { Agriculture }=5 \% \\
\text { Apparel, textiles, merchandis- } \\
\text { ing and design }=2 \% \\
\text { Interior design }=3 \% \\
\text { Math (computational finance) } \\
=3 \% \\
\text { Other }=3 \%\end{array}$ \\
\hline
\end{tabular}

A large percentage of the GP respondents (81\%-87\%) agreed/somewhat agreed that they had strong writing and reading skills, they were familiar with discipline-related vocabulary, they had good research and study skills, and they were good at time management. However, more than half of the GP respondents (53\%) agreed/somewhat agreed that public speaking made them extremely anxious. The UP students were relatively conservative in their ratings. Half of the UP students (50\%) somewhat disagreed with the statement regarding possessing strong writing and reading skills.

Both of the UP and GP students felt positively about the sociocultural aspects of studying in a foreign country; however, the GP students, once again, were more confident in their ratings than the UP students (Figure 2). More than half of the UP respondents, on the other hand, agreed/somewhat agreed (56\%) that they were concerned about adjusting to a new culture. Moreover, a significant percentage of the UP students (95\%) and a large proportion of GP (68\%) agreed/somewhat agreed that they spent more time with international students rather than domestic students.

The needs analysis survey also included open-ended questions in which students elaborated on areas of English that they wanted to improve at INTO WSU, concerns about studying academic courses in English, and their thoughts of ways to improve their English 


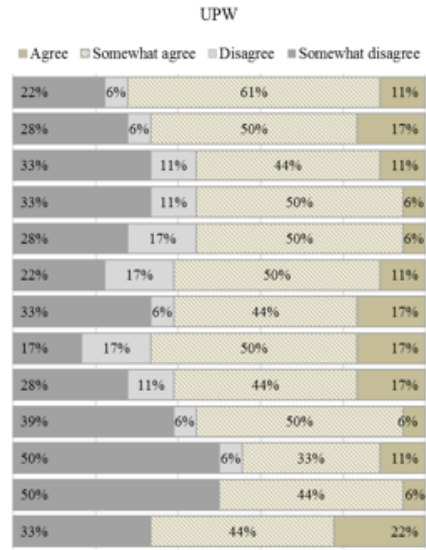

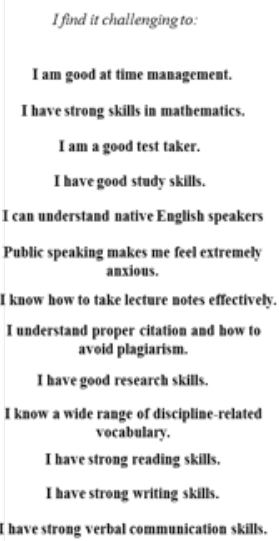

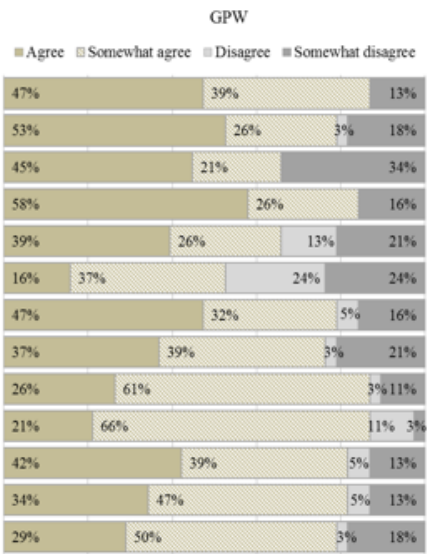

Figure 1. Students' self-reported knowledge about their own L2 and academic competence at entry.

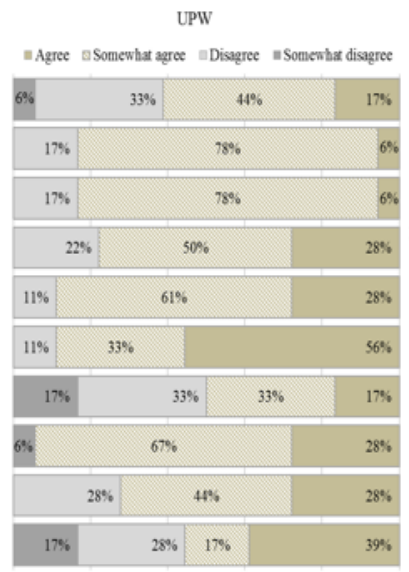

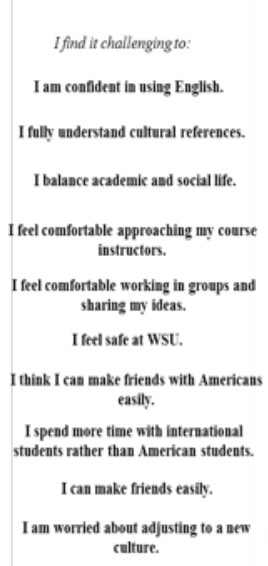

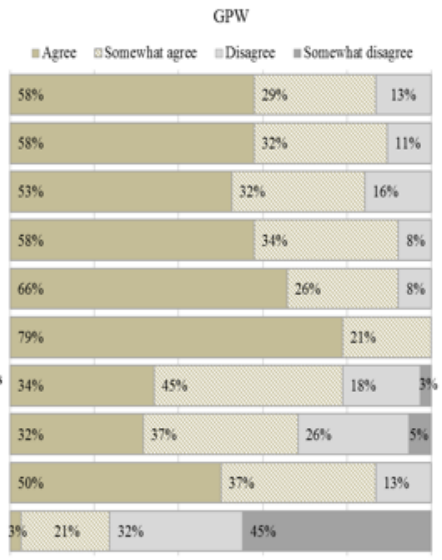

Figure 2. Students' perceptions towards personal and sociocultural aspects of their learning experience at entry.

and academic performance outside of class. The following summarizes the findings from the thematic analysis of data:

- Both the UP and GP participants had similar needs related to language and academic skills. Reading and writing followed by speaking, grammar, listening, and vocabulary were the recurrent aspects of language that UP students hoped to improve at INTO WSU. Interestingly, the GP student population expressed a wider range of needs, including improving their reading, research skills, writing, vocabulary, as well as presentation and discussion skills. Several GP students explained that they wanted 
to improve their speaking skills. Some focused on accent while others emphasized confidence.

- Understanding lectures due to their listening abilities or limited academic vocabulary was a concern for the UP population. Some students named specific courses and explained that they lacked background knowledge in those subjects. Others further explained that reading and writing essays took them a long time, and they were constantly worried about meeting deadlines. While many of the GP students listed similar concerns related to understanding lectures and the lack of background knowledge in some of the selected courses, some specified that they found an enormous difference between the U.S. education style and their countries' and that they were worried about meeting the U.S. education standards. Understanding and using technical terminology and being able to meet degree requirements were some of the other concerns of GP students. A few of the GP students said that their only concern was meeting assignment deadlines.

- Conversation opportunities and specifically interacting with Americans were the most recurring themes regarding UP and GP participants' thoughts about ways to improve their English and academic performance outside of class. Some of the GP participants proposed offering activities, clubs, or groups that they could join to improve their speaking abilities. Reading books, novels, articles, and research papers was also mentioned by the GP participants as means to help them improve their English.

\section{Findings from Individual Interviews: Academic and Sociocultural Experiences at End of the First Semester}

Forty students of the 56 who completed the needs analysis survey participated in the individual interviews (UP: $n=14$, GP: $n=26$ ). The individual interviews showed that UP and GP participants had similar academic and sociocultural experiences. Nonetheless, there were some aspects that were unique to each population.

\section{Academic Challenges}

Understanding lectures. The majority of the UP and GP participants reported that they had difficulties understanding lectures. Some explained that it was challenging for them to follow what instructors said due to limited vocabulary and listening comprehension skills. Some of the UP interviewees stated that it had been difficult for them to catch information due to the speaking speed of some faculty, whereas the majority of GP students attributed the difficulty in understanding to the faculty accents. Another challenge was related to the complexity of the learning process in L2. That is, content learning tasks require higher order thinking (Zohar \& Dori, 2003). Students need to analyze, evaluate, and synthesize the information they receive to create new knowledge. This complex process is further challenging given language demands such as understanding discipline-specific words and phrases. In one of the interviewee's words:

It is hard to understand what the professor is saying. I have to translate the information or the knowledge of my major into mine. That's kind 
of challenging because we are not used to the English lecture. (GP, Computer Science)

Challenging assignments/content. Another recurrent theme was related to specific classes that participants reported being difficult, very demanding, or beyond their academic level. Complaints ranged from challenging or unclear assignments to lack of prerequisite knowledge to be able to succeed in particular courses. The overwhelming majority of UP named a specific course that they felt they were unsuccessful in. For example, one student explained that:

Some of the assignments will be just confusing because it is hard for me to find the information. I always spend a lot of time in the beginning, maybe sometimes even I can't understand anything. (UP, Business)

Other UP participants had similar comments about the difficulty of assignments. They explained that, for example, some of the written assignments required writing a minimum of three pages, but they described the prompts as difficult to understand with no clear guidelines. The GP participants seemed to find some courses beyond their current academic level. To explain, they believed that they lacked the prerequisite content knowledge that would help them navigate new knowledge. A GP student commented that:

My XXX class... I think I am taking a harder one than what I took in my undergraduate. I think it is not suitable for me because it's hard to understand because my English is not very well as American students. It is hard and I can't understand. (GP, Mechanical Engineering)

Linguistic barriers. Linguistic challenges ranged from limited vocabulary to lack of effective speaking and writing skills. Particular writing struggles for the UP participants were lack of schema to write about specific topics and difficulties synthesizing information and organizing their essays. For example, one student explained:

[My] big challenge is the writing part... the essay part. It is very hard. Sometimes I don't know the topic background. So sometimes it is hard for me to write a perfect essay. (UP, Business)

Another UP student majoring in humanities explained that although he attended an international school in his home country in which English was the medium of instruction and attended a year of high school in Los Angeles, "language and vocabulary are still the biggest challenge" for him. The GP students found writing research papers challenging. One GP interviewee majoring in architecture commented that "the most challenge is writing a research paper. I didn't do a research paper before. I think that's the first hardest thing to deal with in the US" Additionally, speaking with clarity and confidence seemed to be a concern to both GP and UP participants mainly due to accent-related issues.

Lack of personalized interaction with faculty. This theme particularly emerged in the UP interviewees' data when they were asked if they received language support from faculty. Some general education classes in freshmen year tend to be large. UP students felt lost to be in such a setting. One student explained: 
We have 300 students in the class, so they [faculty] don't give much support. We have to study by ourselves maybe just go through the dictionary. (UP, Communication)

Another student added "faculty professor class is huge and you can't talk with them at that time" (UP, Humanities).

\section{Sociocultural Challenges}

Students seemed to have positive sociocultural experiences at WSU and in the small college town of Pullman. They shared that they felt safe and found the community to be friendly. One student mentioned:

Teachers and people are very nice here. They just can't understand your language... maybe if it's not very good, they would talk slowly and explain to you the words because I heard that the people in the big cities are not as kind as in here. (UP, Communication)

Nonetheless, a theme that emerged from the UP and GP data was difficulty in making friends and interacting with Americans. The majority of the interviewees stated that they found it difficult to make friends with domestic students because of language barriers and cultural differences. Some added that they do get to interact with Americans in the classroom, dormitory, and other places such as the gym and dining halls, but they said that they interact more with international students or individuals from their own country or culture. The following quotes capture how students felt about this matter:

Making friends with Americans is hard. First because of my language. I can't really understand, so maybe they are talking, and I don't know how to chat with them. And the other thing is that we have one day three hours in the class, and maybe after class we all leave, and we can't real make friends with them. I think it is a little bit difficult. (UP, Business)

I'm trying. During the class time, we have like group work and we talk to each other. We just talk with them, but we don't really become friends. I think it is a challenge. (UP, Humanities)

It is hard. Because we have different thinking styles and speaking styles. Our speaking is slow and not enough words for a conversation. (GP, Computer Science)

\section{Language and Academic Support}

Some of the interview questions asked students about the language and academic support they received. The following summarizes the interviewees' experiences in their university courses and English classes.

Support from university courses. The majority of the interviewees explained that they did not receive language support from faculty teaching university courses. They specifically mentioned that they did not receive feedback on written assignments; they were just given a score. However, many of the GP participants felt that their major courses 
helped them improve their communicative skills due to collaboration and teamwork. They also mentioned that preparing for and giving presentations as well as reading academic articles helped improve their speaking and vocabulary. In terms of academic help, both UP and GP students stated that they either spoke with their instructors after class (not in class), visited faculty occasionally during office hours, or sent emails. They said that when they sought assistance, instructors responded and provided help. One UP student majoring in business commented on this by saying, "If you try to ask, the teacher will help. Just don't be shy. I was shy in the beginning, and the teacher is very nice. Don't be scared just go and ask her." Another GP student from computational finance described faculty as helpful "because when I tell them I am a pathway student, they were very grateful to help us."

Support from language courses. Both UP and GP participants found their English classes helpful. The UP students explained that their English class helped them improve their writing, listening comprehension, and understanding assignments from their university courses:

My XXX class is definitely helping because before I took that class, I didn't know anything about writing an essay, and all other classes require to write an essay. As a student, I didn't know anything, but my teacher helps me and teach me a lot of skills like the Chicago style. She helped me a lot. (UP, Communication)

That class helped me with the writing part. I feel like I can write a lot better than when I was in China, and also helped with my listening ability like when the teacher talks in the class. I think the class helps me catch the real college class. I think it is very helpful. I think studio hours help us with homework that is confusing. I think studio hours are very helpful. (UP, Business)

It helps me how to write an essay and get better, and you know I studied high school in Las Vegas, but the essays in high school and college are different. So when I went to WSU, the first time I wrote was very bad, but now she teaches me how to write and my writing is good. (UP, Business)

The GP students reported similar positive experiences about their English classes. They explained that they helped them with their research skills, grammar, and reading skills.

We learn summary and critique. This is very helpful. Every time I have a conference with XXX, and she has a great patience to help me to reword my paper or other assignments. That's very great! Really helpful. (GP, Computer Science)

I had no idea how to write a research paper before I came to the US. XXX's class helped me a lot how to write a research paper, and helped me to find sources, and how to have a well-organized research paper. And one of my weaknesses in writing I always forget to explain some sources in my 
research paper or in the article, so I think it is helpful. (GP, Mechanical Engineering)

I learned a lot of skills about writing or reading... especially reading. My reading skills improved during the semester. (GP, Computational Finance)

It's helpful in many parts. We need to write a research paper, and she taught us about the format, grammar, and organization. Not only the writing, we read articles, and learn how to think when reading an article. (GP, Electrical Engineering)

\section{Recommendations for Improvement}

The interview also included questions about students' own view of a supportive learning environment and recommendations to the university to improve, which are summarized as follows:

Smaller classes. Putting pathway students in smaller classes was a common theme in the UP students' data. In one of the UP student's words:

I prefer some small lectures not like 300 students, maybe 30 or 40 students, that size of class. Then that would be good because at least the professor can meet and can know our faces. And 300 is.... the first time I went into that classroom, I was freaking out. At least not in pathway I mean. (UP, Communication)

Mindful selection of courses. As pointed out earlier, some pathway students found some courses difficult. Participants recommended selecting courses that would be appropriate for this population. One student elaborated:

English class in here [in the academic English program], they know we are international students, but in my XXX or other classes, they don't know there are pathway students in there. And they talk too fast. Maybe choose which courses the pathway students to go to better than to tell the teacher to be aware there are pathway students in their classes because the class is for the students and most of them are American students. So they can't because there are some pathway students to talk easier or something. I think we have to fit in with the class, but maybe if some of the classes are too hard, they are not appropriate in the first year... maybe like the [XXX course] we can put it in the second year after we practice English more. Choose not too hard courses for first year pathway students. (UP, Business)

Ability to self-select courses. This was specifically common in the GP students' data. One student explained that "The only thing is about the selection of courses should be given to the students even though they are pathway students, so that they are not wasting their credits" (GP, Computer Science). 
Tutoring opportunities. Some of the participants suggested providing more tutoring opportunities for pathway students to help them with content.

Clear guidelines for assignments. Several participants explained that they wished that their major professors provided clear guidelines for assignments and shared sample work.

Out-of-class activities to interact with domestic students. Both UP and GP students recommended offering more activities to interact with domestic students and practice their speaking.

Other. Other suggestions were related to getting more student advisors, explaining U.S. academic expectations clearly, offering sessions or classes on study skills and academic strategies, and recruiting former or senior students to help with specific courses.

\section{Findings from the Follow-Up Survey: Academic and Sociocultural Challenges Experienced during Midterms in Semester Two}

This section reports on results from the follow-up survey, which was administered to track the academic and sociocultural experiences of pathway students after midterms during their second semester. Fifty-one students from the 56 that completed the needs analysis survey at entry responded to this survey (UP: $n=15$, GP: $n=36$ ). Students were asked to report academic challenges as well as sociocultural issues by indicating their level of agreement with the statements listed in Figures 3 and 4. Survey results demonstrated that more than half of the UP either agreed/strongly agreed (54\%-67\%) with the listed academic challenges (Figure 3). Paraphrasing and using proper citation rules to avoid plagiarism, participating in classroom discussions, performing well on assignments, and understanding lectures to instructors' accent or speed seemed to be the most challenging for the UP population. The GP participants' agreed/strongly agreed ratings ranged from $44 \%$ to $66 \%$. Some of their challenges were paraphrasing and using proper citation rules to avoid plagiarism as well as difficulties in understanding lectures due to limited vocabulary.

Common sociocultural challenges (Figure 4) that the UP participants agreed/strongly agreed with included getting access to ethnic food (74\%), understanding U.S. medical insurance (67\%), making friendships with Americans (67\%), learning how to interact with Americans properly (60\%), and adjusting to the American culture (60\%). For the GP participants, challenges included keeping up with finances $(69 \%)$, maintaining contact with family in their home country $(69 \%)$, getting access to ethnic food $(67 \%)$, and being understood when speaking in English (59\%).

Another question in the follow-up survey asked participants to indicate how frequently they sought help from faculty and advisors and utilized services such as the tutoring center. Based on the results presented in Figure 5, a small percentage indicated that they very frequently or frequently made use of the services provided or sought help from faculty and advisors.

\section{Discussion and Implications}

This study attempted to explore the academic and sociocultural experiences of the first cohort of international students in UP and GP programs. Results from this study are consistent with the literature on the challenges faced by international students in 
UPW

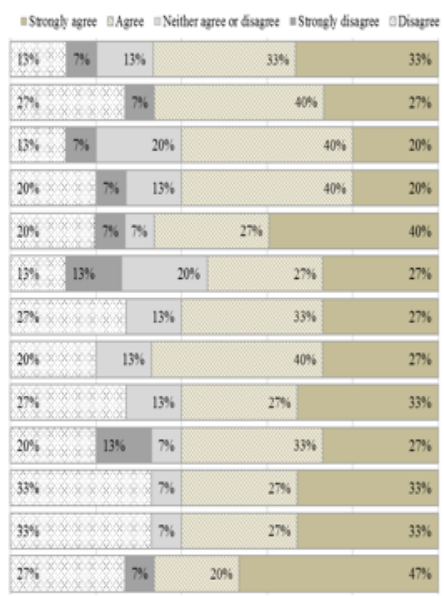

GPW

\begin{tabular}{|c|c|c|c|c|c|}
\hline $25 \%$ & \multicolumn{2}{|c|}{$33 \%$} & $8 \%$ & $17 \%$ & $1 \%$ \\
\hline $22 \%$ & \multicolumn{3}{|c|}{446} & $19 \%$ & $14 \%$ \\
\hline $11 \%$ & $42 \%$ & \multicolumn{2}{|c|}{$22 \%$} & $1 \%$ & $8 \%$ \\
\hline $19 \%$ & $31 \%$ & \multicolumn{2}{|l|}{$25 \%$} & $14 \%$ & Allo \\
\hline $22 \%$ & $28 \%$ & \multicolumn{2}{|l|}{$14 \%$} & $19 \%$ & $17 \%$ \\
\hline $19 \%$ & $36 \%$ & \multicolumn{2}{|c|}{$11 \%$} & $22 \%$ & $11 \%$ \\
\hline $11 \%$ & $4 \%$ & \multicolumn{2}{|c|}{$14 \%$} & $1 \%$ & $14 \%$ \\
\hline $19 \%$ & $31 \%$ & \multicolumn{2}{|l|}{$14 \%$} & $1 \%$ & $25 \%$ \\
\hline $2 \%$ & \multicolumn{2}{|l|}{$33 \%$} & \multicolumn{2}{|r|}{$17 \%$} & $17 \%$ \\
\hline $25 \%$ & \multicolumn{2}{|c|}{$33 \%$} & $17 \%$ & $19 \%$ & $11 \%$ \\
\hline $17 \%$ & \multicolumn{2}{|l|}{$4 \%$} & $14 \%$ & $1 \%$ & $8 \%$ \\
\hline $8 \%$ & \multicolumn{3}{|c|}{$22 \%$} & $19 \%$ & $1 \%$ \\
\hline $19 \%$ & \multicolumn{2}{|l|}{$39 \%$} & $8 \%$ & $19 \%$ & $14 \%$ \\
\hline
\end{tabular}

Figure 3. UP and GP academic challenges in their second semester.

UPW

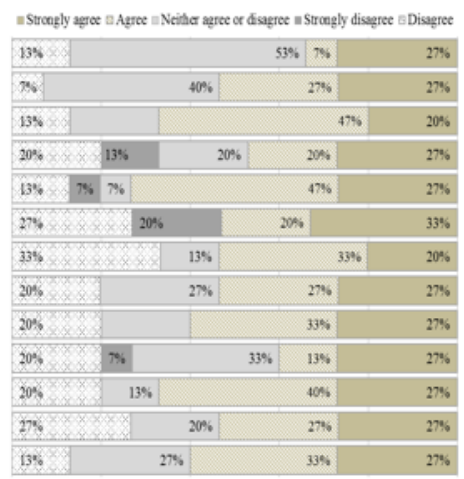

If fud it challenging to:

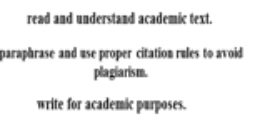

communicate clearty due to mọ pronunciation. participate in chassroom dikcussions. approach my course instructers to ask g̨uestions. perform well on quizes.

perform well on class assigaments.

uderstand instructions on class asigaments. beep op with assiguments

uderstand lectures due to my linited vocabolary.

undentand lectures dee to the difficulty of the coatent understand lectures due to instractors' accent or speed.

Figure 4. UP and GP sociocultural challenges in their second semester.

U.S. higher education (e.g., Caplan \& Stevens, 2017; Perry et al., 2016). Concerning the first research question, students had high expectations regarding their academic and sociocultural experiences in their host country as was demonstrated by the needs analysis survey. Since students were at the beginning of their academic journey in a new country, they were in the "honeymoon" stage filled with feelings of excitement and euphoria (Hommadova, 2017). In the same survey, the UP students indicated a range of linguistic and academic needs related mostly to improving their language skills. In addition to refining their linguistic abilities, the GP students had a wider range of academic needs including developing their research, presentation, and discussion skills. Recurrent 


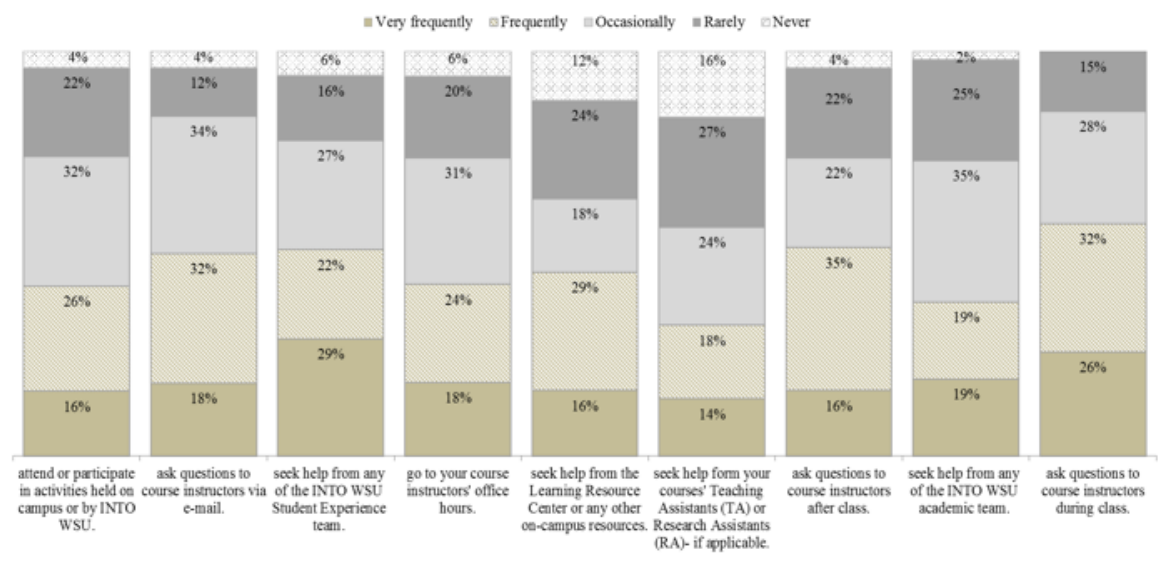

Figure 5. Frequency of support services sought by UP and GP students.

concerns at entry were understanding lectures and meeting assignment deadlines. In terms of ways to improve their English, students proposed offering more opportunities to interact with Americans. To sum up the initial results, students expressed different needs and felt positive about their perceived abilities. Nonetheless, as noted by Brown (1995), student needs are not fixed. They fluctuate and shift as a result of various personal and institutional variables.

The second research question attempted to capture pathway students' sociocultural and learning experiences towards the end of their first and second semesters. Various challenges faced by UP and GP students came forth in the individual interviews and followup survey results. Some of the major challenges, which are in alignment with the literature (e.g., Caplan \& Stevens, 2017; Kuo, 2011; Lin \& Scherz, 2014), were related to understanding lectures and completing assignments successfully.

In addition to these common obstacles, pathway students face additional challenges that are unique to this population. While international students complete their English language programs and then matriculate into their degree programs, international students in the pathway system refine their English and take university courses simultaneously. Pathway programs provide students with the opportunity to develop necessary linguistic skills to be successful in academia. However, students in such programs are immersed in a regular university classroom from the beginning of the semester while working on enhancing their linguistic skills. This results in unique needs and challenges for this population of international students. As the data suggests, UP and GP students at the beginning of their semester were under the impression that they were ready to undertake the challenge of studying in the United States. As the semester progressed, they began to realize the difficulty of listening to lectures or completing an assignment in English. Moreover, balancing between the refinement of linguistic skills and academic courses can be overwhelming. In such settings, students need to keep up with their language courses and make progress in their university courses simultaneously. It is particularly challenging for the GP students as they need to receive a grade point average of 
3.0 in order to progress to the next pathway semester or move out of pathway. Additionally, selection of courses is another challenge for this population. UP and GP courses are preplanned for this population. Students might be unable to change their courses if they find them difficult or unrelated to their majors.

In terms of students' sociocultural experiences, results showed that there is a need to offer more interactive opportunities to bridge the cultural gap between domestic and international students. A few of the students mentioned that they enjoyed classroom teamwork because that was the only time they interacted with Americans. More opportunities to interact with American students outside of class may not only boost students' confidence, but also improve their linguistic and social skills.

Since the adaptation of the pathway system, ongoing efforts are being made to improve the academic and sociocultural experiences of students at INTO WSU:

- Curriculum adaptation: The pathway curriculum has been constantly revisited and updated since the launching of the pathway programs. Revisions are based on input from students, course instructors, and program evaluations. One mandated assignment that was added and should be noted here is "syllabus analysis" to identify major assignments in university classes. This assignment not only help students understand assignment requirements, but also provides their English language faculty with necessary information about pathway students' academic courses so that they can offer support accordingly. New courses for UP and GP students such as "Academic English for Engineering" and "English for Business" have been developed to improve students' communication skills and vocabulary in those contexts. Additionally, a "Study Skills for University Success" course has been designed to help students be more successful in their university courses.

- Studio hours: Since students in the two-semester UP take one language course per semester, more individual interaction and support from faculty in the academic English program was ensured through studio hours. During the studio hours (5 hr), the teacher provides assistance with, for example, understanding assignments from academic courses taken concurrently, using library and Internet resources to locate credible sources, editing written work, and improving individual pronunciation difficulties.

- Learning Resource Center: This tutoring center has been established to help students with both language and content. It offers ESL tutoring as well as customized tutoring for pathway students, connects them with already existing university support services, and works to build out new services needed based on the everchanging demographics of students.

- Advising: Student advisors take care of students' academic and personal wellbeing. They monitor students' academic progress, identify struggling students, and advise them on different types of issues including academics, culture, time management, and organization. More advisors are to be hired to help support and advise students.

- Student experience activities: A student experience team was established to involve pathway students in social events and connect them with the community. 


\section{Conclusion}

To conclude, the trend of offering pathway programs at U.S. universities has been increasing over the past decade. Such programs provide international students with a soft landing spot at institutions of higher education where they receive a high-level of support services while they refine their academic and language skills in preparation for university study. After successful completion of pathway programs, students are mainstreamed into their degree programs. This descriptive research study aimed to assess international undergraduate and graduate students' needs and specifically their academic and sociocultural experiences in pathway programs during their first two semesters at INTO WSU. Findings from the present study can help inform other U.S. universities that have already adopted or are considering the establishment of pathway programs. This study focused on students' own perceived needs and experiences. Future research can also assess factors that correlate with academic success such as pathway students' entry grade point averages and English language proficiency scores. Other future research may explore pathway programs from the perspectives of both faculty for English language learners and regular faculty.

\section{References}

Altbach, P. G. \& Wit, H. (2017). Trump and the coming revolution in higher education internationalization. International Higher Education, 89, 3-5.

Banjong, D. N. (2015). International students' enhanced academic performance: Effects of campus resources. Journal of International Students, 5(1), 132-142.

Bertram, D. (2012). Likert scales ... are the meaning of life.

Braun, V. \& Clarke, V. (2006). Using thematic analysis in psychology. Qualitative Research in Psychology, 3(2), 77-101.

Brown, J. D. (1995). The elements of language curriculum: A systematic approach to program development. Heinle \& Heinle, New York, NY.

Caplan, N. A. \& Stevens, S. G. (2017). "Step out of the cycle": Needs, challenges, and successes of international undergraduates at a US university. English for Specific. Purposes, 46, 15-28.

Chen, J. (2018). Exploring Chinese international students' sense of belonging in North American postsecondary institutions.

Gebhard, J. G. (2012). International students' adjustment problems and behaviors. Journal of International Students, 2(2), 158-164.

Hommadova, A. (2017). Phases of cultural adjustment of East Asian students. Journal of International and Advanced Japanese Studies, 9, 171-192.

Kuo, Y. (2011). Language challenges faced by international graduate students in the United States. Journal of International Students, 1(2), 38-42.

Kusek, W. A. (2015). Evaluating the struggles with international students and local community participation. Journal of International Students, 5(2), 121-131.

Lawson, C. (2016). New initiative will enhance WSU diversity, global reach.

Lin, S. Y. \& Scherz, S. D. (2014). Challenges facing Asian international graduate students in the US: Pedagogical considerations in higher education. Journal of International 
Students, 4(1), 16-33.

Partnerships, I. N. T. O. U. (2018). About INTO.

Perry, C. J. (2016). Comparing international and American students' challenges: A literature review. Journal of International Students, 6(3), 712-721.

Perry, C. J., Weatherford, J., \& Lausch, D. (2016). Academic concerns. pages 192-197.

Richards, J. C. (2017). Curriculum development in language teaching. Cambridge University Press, Cambridge, UK.

Urban, E. L. \& Palmer, L. B. (2014). International students as a resource for internationalization of higher education. Journal of Studies in International Education, 18(4), 305-324.

$\mathrm{Wu}$, H. P., Garza, E., \& Guzman, N. (2015). International student's challenge and adjustment to college. Education Research International, pages 1-9.

Zhou, Y., Frey, C., \& Bang, H. (2011). Understanding of international graduate students' academic adaptation to a U. S. Graduate School. International Education, 41(1), 76-84.

Zohar, A. \& Dori, Y. J. (2003). Higher order thinking skills and low-achieving students: Are they mutually exclusive? The Journal of the Learning Sciences, 12(2), 145-181.

\section{Author biography}

Eman Elturki is the Associate Director of Curriculum and Assessment and faculty at INTO WSU. Her research interests include exploring second language development using corpus linguistics as a methodology, English language teaching and learning, and international student success.

Yang Liu is IALC faculty at INTO WSU. Her research focuses on second language acquisition in adults and culture influence on English language learning.

Justyna Hjeltness is IALC faculty at INTO WSU. Her current research interests include integration of international students into a university setting.

Kate Hellmann is the Academic Director at INTO WSU. Her research focuses on using sociocultural theory as a lens for international student success in higher education. 